\title{
The Effect of Educational Strategies Targeted for Nurses on \\ Pain Assessment and Management in Children : An Integrative Review
}

\section{Amponsah, Abigail Kusi}

2019-12

Amponsah , A K , Björn , A , Bam , V \& Axelin , A 2019 , ' The Effect of Educational

Strategies Targeted for Nurses on Pain Assessment and Management in Children : An

Integrative Review ' , Pain Management Nursing , vol. 20 , no. 6 , pp. 604-613 . https://doi.org/10.1016/j.pmn.2019.0

http://hdl.handle.net/10138/323901

https://doi.org/10.1016/j.pmn.2019.03.005

publishedVersion

Downloaded from Helda, University of Helsinki institutional repository.

This is an electronic reprint of the original article.

This reprint may differ from the original in pagination and typographic detail.

Please cite the original version. 


\title{
The Effect of Educational Strategies Targeted for Nurses on Pain Assessment and Management in Children: An Integrative Review
}

\author{
Abigail Kusi Amponsah, MSc, RGN, FGCNM ${ }^{*},{ }^{\dagger}$, Annika Björn, MNSc, RN ${ }^{\ddagger}$, \\ Victoria Bam, PhD, RN, FGCNM ${ }^{\dagger}$, Anna Axelin, PhD, RN \\ * Department of Nursing Sciences, University of Turku, Turku, Finland \\ ${ }^{\dagger}$ Department of Nursing, Kwame Nkrumah University of Science \& Technology, Kumasi, Ashanti, Ghana \\ ${ }^{\ddagger}$ Helsinki University Hospital, HUCH Perioperative, Intensive Care and Pain Medicine, Helsinki, Finland
}

\section{A R T I C L E I N F O}

\section{Article history:}

Received 30 June 2018

Received in revised form

22 January 2019

Accepted 31 March 2019

\begin{abstract}
A B S T R A C T
Background: Nurses play an important role in children's pain assessment and management because they spend the majority of the time with them and provide care on a 24-hour basis. However, research studies continue to report on nurses' inadequate assessment and management of children's pain, which may be partly attributed to their insufficient education in this area.

Objectives: This integrative review sought to examine the effect of strategies used in educating nurses on pediatric pain assessment and management.

Design: An integrative review.

Data Sources: Cumulative Index to Nursing and Allied Health Literature, Cochrane, PubMed/ Medline and Scopus.

Review/Analysis Methods: Four databases were searched up to February 2018 based on a prescribed eligibility criteria. The review included 37 studies with varied methodologic quality.

Results: Our findings revealed that various types of educational strategies improve nurses' knowledge, attitudes, and practice of pain assessment, management, and/or documentation.

Conclusions: Developing a responsive program that includes expectations of beneficiaries, integrating it into existing facility training systems and delivering it through multidisciplinary collaboration, offers the benefit of securing sustainability of the educational gains.
\end{abstract}

๑) 2019 American Society for Pain Management Nursing. Published by Elsevier Inc. All rights reserved.

\section{Introduction}

In spite of advanced technologies and research on pain (Argoff, 2014; Chiaretti et al., 2013), children continue to experience needless pain during hospitalization and in ambulatory settings (Birnie et al., 2014). Unrelieved pain in children can lead to negative psychophysiologic consequences and increased health care costs (Cousins, 2012; Twycross, 2010) and contribute to the development of chronic pain syndromes, which may alter children's responses during future painful experiences (Bushnell, Čeko, \& Low, 2013).

The pediatric pain experience presents unique challenges and opportunities because of the complex interaction of developmental, physiological, behavioral, psychosocial, and situational factors that are different from adults (Jain, Yeluri, \& Munshi, 2012). Children encompasses an extremely broad group from premature neonates to

Address correspondence to Abigail Kusi Amponsah, MSc, RGN, FGCNM, Department of Nursing Sciences, University of Turku, Turku, Finland.

E-mail address: abkuam@utu.fi (A. Kusi Amponsah). adolescents. Apart from marked age-related changes affecting all aspects of pain management (Mazur, Radziewicz Winnicki, \& Szczepański, 2013), variations also abound in children's ability to communicate the source and intensity of their pain (Noel, Chambers, McGrath, Klein, \& Stewart, 2012). Thus they are more likely to be underassessed and inadequately managed for their pain (Srouji, Ratnapalan, \& Schneeweiss, 2010).

Nurses spend the majority of the time with hospitalized children and provide care on a 24-hour basis (Ekim \& Ocakci, 2013). Hence, they are uniquely positioned to directly affect the adequacy of children's pain management through pain assessment, planning, implementation and evaluation of interventions. However, research studies continue to report of nurses' inadequate pain assessment and management (Aziato \& Adejumo, 2014). A major contributory factor to this observation is the limited education during nursing training (Abed ElRahman, Al Kalaldeh, \& Muhbes, 2013) and the lack of continuing education for nurses on pain management (Twycross, 2013).

Education of nurses on pediatric pain assessment and management therefore presents as one of the viable opportunities to 
bridge the gaps in knowledge, attitudes, and practices (Huth et al., 2010). Logically an educational program should result in learning of a desired behavior (Cilliers \& Herman, 2010). Nevertheless, some studies have found that education about pain does not always result in an improved behavior change (Francis \& Fitzpatrick, 2013; Overmeer, Boersma, Denison, \& Linton, 2011). Among the myriad reasons that may account for this observation, the method of teaching has been highlighted as a major factor in determining educational outcomes (Hightower, Lloyd, \& Swanson, 2011).

In our attempt to explore the research synthesis on educational interventions targeted for nurses on children's pain assessment and management, no review was found in the area. Hence, this integrative review sought to examine the effect of strategies used in educating nurses on pediatric pain assessment and management.

\section{Review Questions}

Our review sought to answer the following questions:

1 What is the nature of published studies conducted in the field of nursing education on pediatric pain assessment and management?

2 What type of outcomes have been assessed from these studies?

3 Which aspects of the education contributes to its effectiveness?

\section{Methods}

\section{Protocol}

Before the review, a detailed protocol was developed using the guidelines provided by Preferred Reporting Items for Systematic reviews and Meta-Analyses for Protocols 2015 (PRISMA-P 2015).

\section{Inclusion Criteria}

Experimental and nonexperimental studies involving nursing educational interventions on pediatric pain assessment and management and their reported outcomes were eligible for inclusion.

\section{Search Strategy}

A comprehensive search was conducted on four databases: Cochrane Central Register of Controlled Trials, CINAHL (Cumulative Index to Nursing and Allied Health Literature), PubMed/Medline, and Scopus up to February 28, 2018. The search was restricted to English, Finnish, and Swedish languages.

\section{Search Terms}

The review questions were analyzed into major components using the Population, Intervention, Comparison, and Outcome framework (Higgins \& Green, 2008). The search was then launched with every keyword individually and then combined to get a larger pool of results. Because of the peculiarities of each database, the search strategy was modified as and when necessary using terms relating to nursing, midwifery, staff, student, education, pain assessment, management, and children.

\section{Study Selection}

The retrieved studies were exported into Mendeley reference manager, after which duplicate articles were removed. The titles and abstracts of the studies were independently screened by two reviewers (A.K.A. and A.B.) against the study's inclusion criteria.
Studies for potential inclusion in the review were decided based on discussions among the reviewers. Full-text articles of all potential studies were examined by the reviewers before agreeing on the inclusion of 37 studies in this review. The process for study retrieval and selection is presented in Figure 1.

\section{Critical Appraisal}

Two reviewers (A.K.A. and A.B.) evaluated the studies using different critical appraisal tools for the different study designs. Reviewers selected the most appropriate tool based on discussions among the research group. Each item on the appraisal tools was evaluated as "yes" (with a score of 1 ), "partly yes and no" (with a score of $1 / 2$ ), and "no" and "cannot determine" (score of 0 ). In situations where an item had two subquestions with opposing responses (i.e., yes and no), the "partly yes and no" option was chosen. Items with "not applicable" responses were not scored.

The 20-item Wiley appraisal tool (Greenhalgh, Robert, Macfarlane, Bate, \& Kyriakidou, 2004, p. 234) was applied to action research studies, whereas the 13-item Mixed Methods Appraisal Tool (Pluye, Robert, Cargo, \& Bartlett, 2011) was used for mixed methods studies. Controlled intervention studies (randomized controlled trials [RCT] and quasi-experimental studies with controls) and pretestposttest studies with no controls were evaluated with the National Institute of Health's quality assessment tools designed for such studies (National Heart, Lung and Blood Institute, n.d.). The total attainable appraisal score for each controlled intervention study ranged from 10 to 13 on the 14-item instrument, whereas that of pretest-posttest studies with no control extended from 9 to 10 on the 12-item scale. Differences in the denominators were attributable to questions that were considered nonapplicable to specific study designs, interventions, and outcome assessment modalities.

Critical appraisal of 5 controlled intervention studies ( 3 RCTs and 2 quasi-experimental studies with controls), 20 pretest-posttest studies with no controls, 10 action research studies, and 2 mixed methods studies were conducted. The highest attainable critical appraisal score of each study was divided by 3 and converted into percentages for standardization purposes. The authors designed a categorization scheme because there were no published guidelines on this approach. Scores from 0 to $33.3 \%$ were graded as low (with high risk of bias), those from $33.4 \%$ to $66.7 \%$ were rated as moderate (with moderate risk of bias), and those from $66.8 \%$ to $100 \%$ as high (with low risk of bias). A consensus was reached among authors not to exclude studies on the basis of these quality categorizations.

\section{Data Extraction}

Recommendations by the Center for Reviews and Dissemination (Tacconelli, 2010) guided data extraction and the following were retrieved from individual studies: author(s), year of publication, methodologic quality rating, study design, sample characteristics, country, intervention deliverer, delivery mode, content, frequency, duration, measured outcome(s), and findings.

Classification of the delivery mode of the educational intervention was based on the template for intervention description and replication guidelines (Hoffmann et al., 2014). Interventions were categorized as being delivered on the basis of individual versus group; face to face, distance, or combination; and being interactive or noninteractive.

The educational content was classified based on five central themes: basic principles, pain assessment, pharmacologic pain management, nonpharmacologic pain management, and documentation. Basic principles covered areas such as pain definitions, types, pathophysiology, theories, benefits of pain management, 


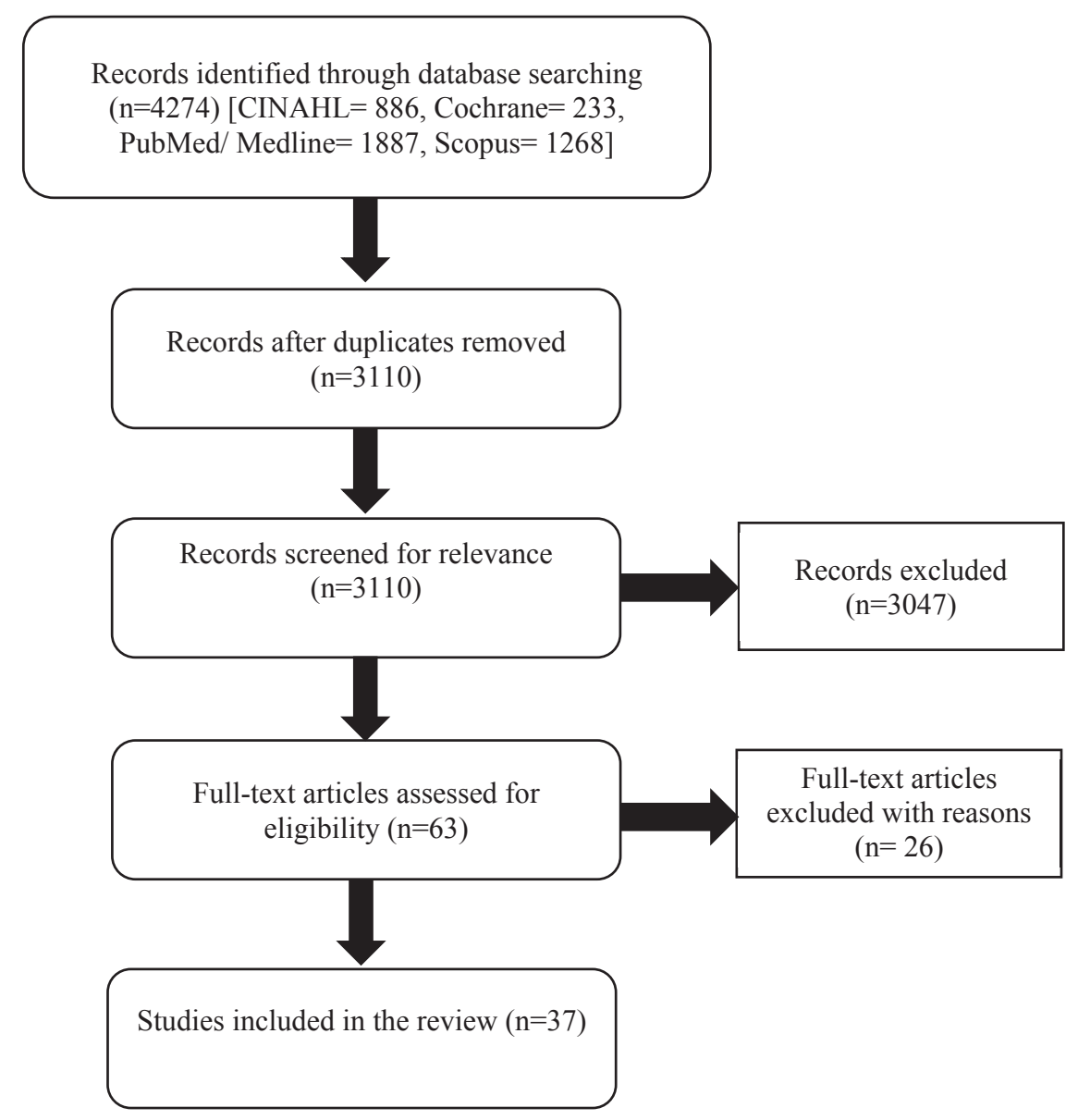

Figure 1. Study selection process.

brain and cognitive development of children, barriers, communication, and ethicolegal considerations.

The components of the three major outcomes (knowledge, attitude, and practice) have been described as follows: Knowledge was composed of basic facts or information on basic principles, pain assessment, pharmacologic pain management, nonpharmacologic pain management, and documentation. Attitude was composed of beliefs, perception, satisfaction with pain assessment, management, and/or documentation. Practice referred to the execution of pain assessment, management, and/or documentation.

\section{Data Synthesis}

Because of the methodologic heterogeneity of the included studies, it was not possible to combine the individual study results for a possible meta-analysis. Thus a narrative summary of the results was presented. Qualitative content analysis of the interventions that resulted in positive outcomes was also facilitated using NVivo Version 12 software (QSR International Pty Ltd., London, UK).

\section{Results}

The characteristics and findings of the 37 included studies have been presented in Table 1.

\section{What Is the Nature of Published Studies in This Field?}

Majority of the studies were quasi-experimental (22 of 37) and of moderate methodologic quality ( 28 of 37 ). Studies were mainly carried out in developed countries (32 of 37) and published between 1996 and 2017. Slightly more than a third of participants were registered nurses ( 14 of 37). Of the 29 studies that reported on the sample sizes, the numbers ranged from 10 to 366 .

Sixteen percent of the educational interventions were delivered by research team members ( 6 of 37) and program educators (6 of 37) from different health care disciplines. Forty-three percent of studies (16 of 37) did not report on the intervention deliverer. A little more than half of the interventions (19 of 37) occurred once, and the frequency of 9 studies were not reported. The duration of interventions varied from less than 30 minutes to 37 hours in 25 studies and was unreported in 12 studies. Of the 27 studies that reported on the delivery mode, the majority occurred in groups (23 of 27), were organized through face-to-face mode (22 of 27), and used interactive teaching and learning methods (19 of 27). Much of the educational content centered on basic principles of pain assessment and management ( 25 of 37 ), pain assessment ( 28 of 37), pharmacologic pain management (29 of 37), and nonpharmacologic pain management (28 of 37).

What Types of Outcomes Have Been Assessed from These Studies?

More than half of the studies reported on knowledge (19 of 37), attitude (20 of 37), and practice (30 of 37) of pain assessment, management, and/or documentation.

Other outcomes that were assessed included staff evaluation of the educational program (3 of 37), patient/family satisfaction with pain management ( 3 of 37), patients' pain report at discharge ( 1 of 37 ), duration of mechanical ventilation (1 of 37), length of hospital 
Table 1

Study Characteristics and Findings

\begin{tabular}{|c|c|c|c|}
\hline Author(s), Year; Country & Study Design; Participants; Sample Size & $\begin{array}{l}\text { Intervention Deliverer; Frequency; } \\
\text { Duration; Delivery Mode; Content }\end{array}$ & Findings \\
\hline Bildner \& Krechel, 1996; USA & $\begin{array}{l}\text { Action research; Nurses, pediatric } \\
\text { residents, social worker, respiratory } \\
\text { therapist, nutritionist; Unspecified }\end{array}$ & $\begin{array}{l}\text { PTM; Unspecified; Unspecified; G, F, I; } \\
\text { PA, PPM, NPPM }\end{array}$ & $\begin{array}{l}\text { Increased compliance in pain assessment (to } 100 \% \text { ) over } \\
1 \text {-year period. Nurses became more assertive in asking } \\
\text { for analgesics \& better able to describe infants' pain. }\end{array}$ \\
\hline $\begin{array}{l}\text { Howell, Foster, Hester, Vojir, \& } \\
\text { Miller, 1996; USA }\end{array}$ & $\begin{array}{l}\text { Mixed method; Nurses, practical } \\
\text { nurses, nursing assistants; } \\
\text { Quantitative: } 11=26 / 39 / 21 \\
\text { Qualitative: } p=3\end{array}$ & $\begin{array}{l}\text { PE; } 5 ; 2.5 \text { hours; G, F, I; BP, PA, PPM, } \\
\text { NPPM }\end{array}$ & $\begin{array}{l}\text { Increased nurses' knowledge, usage of the pain } \\
\text { management forms (by } 77 \% \text { ) \& understanding of } \\
\text { children's pain. The program's Feasibility Rating Scale } \\
\text { (FRS) were rated as moderate in nature. }\end{array}$ \\
\hline Pederson, 1996; USA & $\begin{array}{l}\text { Controlled intervention; Pediatric } \\
\text { nurses; P1 }=54, \text { P2 }=35(21 \text { I, } 14 \text { C) \& } \\
\text { P3 }=24\end{array}$ & PE; $1 ; 2$ hours; G, F, I; NPPM & $\begin{array}{l}\text { Treatment group reported improved knowledge and } \\
\text { use of five nondrug pain management techniques: } \\
\text { breathing, relaxing, distraction, guided imagery, \& } \\
\text { changing perception of painful stimuli; increased } \\
\text { comfort in guiding children's imagery \& changing their } \\
\text { perception of painful stimuli }(p \leq .05) \text {. }\end{array}$ \\
\hline Knoblauch \& Wilson, 1999; USA & $\begin{array}{l}\text { Pre-post with no control group; } \\
\text { pediatric nurses; } \mathrm{P} 1=52 \& \mathrm{P} 2=52\end{array}$ & $\begin{array}{l}\text { Unspecified; } 1 ; 3 \text { hours; G, F, I; BP, PA, } \\
\text { PPM, NPPM, D }\end{array}$ & $\begin{array}{l}\text { Increased time before administration of first analgesic } \\
\text { dose \& between doses of analgesics to patients. }\end{array}$ \\
\hline Simons, 2002; UK & $\begin{array}{l}\text { Action research; Pediatric nurses; } \\
\mathrm{P} 1=10 \& \mathrm{P} 2=10\end{array}$ & $\begin{array}{l}\text { PE; } 1 ; 7.25 \text { hours; Unspecified; BP, PA, } \\
\text { PPM, NPPM }\end{array}$ & $\begin{array}{l}\text { Nurses gained knowledge on pain assessment in } \\
\text { children. They felt their new knowledge increased their } \\
\text { confidence \& assertiveness children's pain } \\
\text { management. }\end{array}$ \\
\hline Gallo 2003; USA & Action research; Nurses; $p=125$ & $\begin{array}{l}\text { Unspecified; } 1 \text {; > } 30 \text { minutes; G, F, N; BP, } \\
\text { PA, NPPM, D }\end{array}$ & $\begin{array}{l}\text { Improved pain assessment adherence rate of } 65 \% \text { and } \\
\text { documentation rates of } 55 \%-60 \% \text { after the intervention. }\end{array}$ \\
\hline $\begin{array}{l}\text { Bachiocco, Gentili, Mastrolia, } \\
\text { Lima, \& Baroncini, 2005; Italy }\end{array}$ & $\begin{array}{l}\text { Pre-post with no control group; } \\
\text { Practical nurses; } \mathrm{P} 1=53 \& \mathrm{P} 2=53\end{array}$ & $\begin{array}{l}\text { Unspecified; } 1 ; 6 \text { hours; Unspecified; } \\
\text { BP, PA, PPM, NPPM }\end{array}$ & $\begin{array}{l}\text { Improved knowledge in most pain topics } \\
\text { (pharmacology, physiology \& pain measurement) } \\
(p \leq .05) .\end{array}$ \\
\hline $\begin{array}{l}\text { Chiang, Chen, \& Huang, 2006; } \\
\text { Taiwan }\end{array}$ & $\begin{array}{l}\text { Pre-post with no control group; } \\
\text { Nursing students; P1 = } 192 \& \text { P2 }=181\end{array}$ & $\begin{array}{l}\text { Instructor; } 1 \text {; } 4 \text { hours; G, F, I; BP, PA, } \\
\text { PPM, NPPM }\end{array}$ & $\begin{array}{l}\text { Improved knowledge (by } 34.4 \% \text { ) of pediatric pain, } \\
\text { attitudes, \& self-efficacy (by 13.7\%) in children's pain } \\
\text { management }(p \leq .05) \text {. }\end{array}$ \\
\hline Simons \& MacDonald, 2006; UK & Action research; Nurses; Unspecified & $\begin{array}{l}\text { PTM; Unspecified; Unspecified; I, F, I; } \\
\text { PA }\end{array}$ & $\begin{array}{l}\text { Improved usage of pain assessment tools }(23 \%-40 \%) \& \\
\text { analgesic prescription. Nurses found the tools very easy } \\
\text { to use with time. }\end{array}$ \\
\hline $\begin{array}{l}\text { Ellis, Martelli, LaMontagne, \& } \\
\text { Splinter, 2007a; Canada }\end{array}$ & $\begin{array}{l}\text { Pre-post with no control group; Nurses, } \\
\text { practical nurses; P1 = } 366 \& \text { P2 }=120\end{array}$ & $\begin{array}{l}\text { Unspecified; } 1 ; 4 \text { hours; Unspecified; } \\
\text { BP, PA, PPM, NPPM }\end{array}$ & $\begin{array}{l}\text { Improved knowledge (by } 3 \% \text { ), use of pain scales \& } \\
\text { documentation. No differences in the nurses' beliefs \& } \\
\text { perceptions regarding pain }(p>.05) \text {. }\end{array}$ \\
\hline Johnston et al., 2007; Canada & $\begin{array}{l}\text { Controlled intervention; pediatric } \\
\text { nurses; P1 = } 141 \& \text { P2 }=90\end{array}$ & $\begin{array}{l}\text { PNC; 10; Unspecified; I, F, I; PA, PPM, } \\
\text { NPPM }\end{array}$ & $\begin{array}{l}\text { Increased knowledge (by } 8 \text { points), rate of pain } \\
\text { documented (by } 43 \% \text { ) \& usage of nonpharmacologic } \\
\text { interventions (by } 11 \% \text { ) in the intervention group } \\
\text { compared with a declining knowledge (by } 1 \text { point), rate } \\
\text { of pain documentation (by } 15 \% \text { ) \& usage of nondrug } \\
\text { measures (by } 1.2 \% \text { ) in their controls ( } p \leq .05 \text { ). }\end{array}$ \\
\hline $\begin{array}{l}\text { He, Vehvilainen-Julkunen, } \\
\text { Pietila, \& Polkki, 2008; China }\end{array}$ & $\begin{array}{l}\text { Pre-post with no control group; Nurses; } \\
\mathrm{P} 1=178 \& \mathrm{P} 2=181\end{array}$ & $\begin{array}{l}\text { LA; } 1 \text {; Unspecified; G, F, N; BP, PA, PPM, } \\
\text { NPPM }\end{array}$ & $\begin{array}{l}\text { Increased usage of nondrug pain relieving strategies } \\
\text { (imagery, positive reinforcement, TENS, touch \& } \\
\text { presence }(p<.05) \text {, positioning, touch, presence \& } \\
\text { helping with activities of daily living). }\end{array}$ \\
\hline $\begin{array}{l}\text { Hong, Murphy, \& Connolly, } \\
\text { 2008; USA }\end{array}$ & $\begin{array}{l}\text { Pre-post with no control group; Nurses; } \\
\text { Unspecified }\end{array}$ & $\begin{array}{l}\text { LA; } 1 ; 20-30 \text { minutes; G, C, I; BP, PPM, } \\
\text { NPPM }\end{array}$ & $\begin{array}{l}\text { Increased satisfaction ratings on nurses' communication } \\
\text { with parents/family (by } 3.7 \% \text { ), explanations of } \\
\text { treatments (by } 4 \% \text { ), \& pain management (by } 1.6 \% \text { ) } \\
(p>.05 \text { ). }\end{array}$ \\
\hline $\begin{array}{l}\text { Maclaren, Cohen, Larkin, \& } \\
\text { Shelton, 2008; USA }\end{array}$ & $\begin{array}{l}\text { Controlled intervention; Nursing } \\
\text { students; } \mathrm{P} 1=58 \& \mathrm{P} 2=50\end{array}$ & LA; $1 ; 25$ minutes; G, F, I; NPPM & $\begin{array}{l}\text { Increased knowledge, number \& quality of CBPM } \\
\text { strategies in the intervention group relative to their } \\
\text { controls }(p>.05) \text {. No differences between groups on } \\
\text { attitudes toward the effectiveness of CBPM strategies } \\
(p>.05) \text {. }\end{array}$ \\
\hline Le May et al., 2009; Canada & $\begin{array}{l}\text { Pre-post with no control group; } \\
\text { pediatric nurses; P1 }=42 \& \mathrm{P} 2=21\end{array}$ & $\begin{array}{l}\text { LA; 3; 60-90 minutes; Unspecified; BP, } \\
\text { PA, PPM, NPPM }\end{array}$ & \\
\hline
\end{tabular}

Risk of Bias; Outcome

Assessment Frequency

oderate; Unspecified

Moderate; 2-3

High; 3

Moderate; 2

Moderate; 3

High; 3

Moderate; 2

Low; 2

Moderate; 4

Moderate; 2

Moderate; >4

Moderate; 2

Moderate; 2

Moderate; 2

Low; $2-3$ 
Pre-post with no control group; Pediatric \& general nurses; P1 $=134$ $\mathrm{P} 2=108$

Unspecified; 1; 2 hours; G, F, I; BP, PA, PPM, NPPM

Improved K\&A $(28.2 \pm 4.9$ to $31.0 \pm 4.6)(p<.05)$, pain documentation (by $21.5 \%-29.8 \%$ ), \& usage of

nonpharmacologic interventions (by $15.2 \%)(p<.05)$. massage, \& positioning) for children's postoperative

Pre-post with no control group; Nurses; Mexica

He et al. 2011: Singapore

$\mathrm{P} 1=106 \& \mathrm{P} 2=79$

$\mathrm{P} 1=134 \& \mathrm{P} 2=112$

hours; G, F, I; BP, PA, PPM,

NPPM

Van Hulle, Wilkie, \& Wang, 2011; USA

Corwin, Kessler, Auerbach, Liang, \& Kristinsson, 2012 USA

Pre-post with no control group; Nurses; $\mathrm{P} 1=24 \& \mathrm{P} 2=21$

Action research; Nurses, physicians, patients, parents; Unspecified Unspecified; BP, PA, PPM, NPPM

Pre-post with no control group; Nurses; $\mathrm{P} 1=27, \mathrm{P} 2=11, \& \mathrm{P} 3=15$

Controlled intervention; Public health nurses; P1 = 53 (31 I, 22 C) \& P2 = 43 $(27 \mathrm{I}, 16 \mathrm{C})$

han, Pielak, McIntyre, Deeter, \& Taddio, 2013; Canada

Deindl et al., 2013: Austria

Scott, Crilly, Chaboyer, \& Jessup 2013; Australia

Nissen \& Dunford 2014; UK

Owens, Smith, \& Jonas, 2014;

Reavey et al., 2014; USA

Vael \& Whitted, 2014; USA
Action research; Nurses, physicians: Nurses: $\mathrm{P} 1=46 \& \mathrm{P} 2=42$, Physician $\mathrm{P} 1=13 \& \mathrm{P} 2=19$

Pre-post with no control group; Nurses; Unspecified

Action research; Nurses; Unspecified

Controlled intervention; Nursing students; P1 = 127 (64 I, 63 C) $\mathrm{P} 2=82(45 \mathrm{I}, 37 \mathrm{C})$

Action research; Nurses, neonatal NPs, CNSs, pharmacists, neonatal fellows, neonatologists; Unspecified
RT; 12 hours; G, F, I; BP, PA, PPM,

NPPM

Unspecified; 1; 2 hours; I, D, N; BP, PA PPM

Unspecified; Unspecified; Unspecified;

Unspecified; Unspecified; Unspecified; Unspecified; BP, PA, PPM, NPPM

Unspecified; Unspecified; Unspecified; Unspecified; Unspecified

PNS; 3; 3 hours; G, F, I; BP, PPM, NPPM

Unspecified: Unspecified: Unspecified: Unspecified; Unspecified

LA; $1 ;<30$ minutes; G, F, N; PA 40 minutes. Reassessment of pain by physicians The percentage of patients in pain receiving any Heavy workload, lack of time, \& child's inability to cooperate were the commonly reported reasons that limited nurses' application of pain relief methods. Increased use of five nonpharmacologic methods (imagery, positive reinforcement, thermal regulation, pain relief $(p<.05)$.

Improved K\&A $(13.1 \pm 3.89-16.7 \pm 4.33)$

postintervention $(p<.05)$.

No difference in all types of preparatory information provided to parents $(p>.05)$. An increase in all nonpharmacologic methods that were being suggested by the nurses to parents.

Improved pain beliefs and simulated pain management practice of nurses \& a decrease in children's pain levels $(p<.05)$. All participants evaluated the program as easy to understand \& use, organized, \& engaging.

Median time to analgesic administration decreased by increased by $70 \%$ \& that of nurses by $7 \%$. Decreased pain reports (by 6\%) from the time of triage until discharge. analgesic increased by $16 \%$ \& those receiving preprocedural analgesia increased by $52 \%$. Patient satisfaction increased by 0.06 .

o difference in nurses' K\&A regarding pediatric pain

reassessment $(p<05)$. No difference in patier

family satisfaction $(p>.05)$.

Increased satisfaction, confidence with pain

.

recommended strategies in the intervention sites $(p<05)$.

An increase in opiate prescription, pharmacologic interventions, \& staff satisfaction without affecting time on mechanical ventilation, length of intensive care stay, \& adverse outcomes.

Improved pain documentation (by about $7 \%$ ), analgesic administration (by 7\%) \& use of nondrug measures (by $8 \%)(p>.05)$.

A 74\% increase in pain tools in care files, 30\% increase in use of pain tools, $26 \%$ increase in documentation of pain relief interventions, \& $55 \%$ increase in the evaluation of interventions.

Slight improvement in knowledge of the intervention group relative to their controls. Perception \& attitudes group roups.

Moderate; 2

Moderate; 2

Moderate; 2

Moderate; 2

Low; 2

Moderate; 3

Moderate; 2

Moderate; 2

Moderate; 4

Moderate; 2

Moderate; 3

Improved frequency of pain assessment \& documentation $(p<.05)$. Nurses used the FLACC pain 
Pre-post with no control group; Nurses, licensed practical nurses; P1 $=22$ $\mathrm{P} 2=20$

Pre-post with no control group; Nurses; $\mathrm{P} 1=89 \& \mathrm{P} 2=69$

Pre-post with no control group;

pediatric nurses; $\mathrm{P} 1=167 \& \mathrm{P} 2=15$ Pre-post with no control group; Nurses \& nurse technicians; Average of 24.2/57

Taddio et al., 2015; Canada

Mixed method; Nurses; Quantitative: P1 $=29 \&$ P2 $=28$, Qualitative: $\mathrm{P} 1 \leq 24$

Heinrich, Mechea, \& Hoffmann, 2016; Germany

Ramira, Instone, \& Clark, 2016: USA
PE; Unspecified; Unspecified; G, F, I; BP. PPM, NPPM

Pre-post with no control group; Nurses: $\mathrm{P} 1=94, \mathrm{P} 2=90, \& \mathrm{P} 3=87$
APN; 3; 3 hours; G, F, I; PA, PPM, NPPM

Unspecified; 1; 2-2.5 hours: C, F, N; BP, PPM, NPPM

PTM; 7; 37 hours; G, C, I; BP, PA, PPM

Unspecified; 2; Unspecified; G, F, I; BP, PPM, NPPM

Unspecified; 3; Unspecified; Unspecified: BP, PA, PPM, NPPM

PE; 1; 30 minutes; G, F, N; BP, PA, PPM

Action research; Nurses, practica nurses; $p=100$

Dongara, Nimbalkar, Phatak, Patel, \& Nimbalkar, 2017; India
, 1: 3 hours: Unspecified; BP, PA, PPM, NPPM
Unspecified; Unspecified; 40 minutes; I, D, N; BP, PA, PPM, NPPM preverbal children.

Improved knowledge $(p<.05) .88 \%$ of all pain assessments at triage, postintervention, \& before discharge were documented. A total of $54 \%$ of participants felt confident in assessing pediatric pain. $88 \%$ reported the program was effective, $96 \%$ noted the content was relevant \& $78 \%$ desired to change their practice.

Improved $\mathrm{K} \& \mathrm{~A}(79 \% \pm 8.13$ to $83 \% \pm 5.33 ; p<.05)$. Reductions in the overall mean pain score for

participants between $\mathrm{T} 1(5.68 \pm 2.08, \mathrm{~N}=25) \& \mathrm{~T} 3$ $(0.98 \pm 1.32, \mathrm{~N}=40) \&$ between $\mathrm{T} 2(4.84 \pm 1.61, \mathrm{~N}=24)$ \& $\mathrm{T} 3(p<.05)$.

Improved pediatric pain $\mathrm{K} \& \mathrm{~A}$ (by $21.4 \%)(p<.05)$.

mproved accuracy in acute pain diagnoses (by 6.3\%) $(p<.05)$. Relevance \& specificity of diagnoses were moderate to high for most records.

Improved knowledge from baseline to pamphlet review phase \& from the pamphlet review to the video review phase $(p<.05)$. Nurses reported being motivated to fully involve parents in procedures \& were generally receptive to information contained in the tools. Nurses ained knowledge \& skills needed in improving pain management practices.

Improved analgesic administration, control of pain ( $(p<05)$

mproved pain documentation at triage (by 76\%) \& \% of patients whose pain was assessed at or before discharge (by $58 \%)(p<.05)$; shortened interval between first pai score \& the time of analgesia administration (from mean of 88 to 29 minutes) $(p<.05)$; slightly shorter time between arrival at the ED \& documentation of first pain score (from 17 to 16 minutes) ( $p=.876$ ). 88\% of patients had pain scores $<2$ at or before discharge compared to $97 \%$ of children post-education $(p<.001)$. Nursing pain knowledge scores increased by about $7 \%$ (77.8\%-83.4\%). Over 18 months, use of topical lidocaine rose from $10 \%$ to $36.5 \%$ for all inpatient admissions. Mean parent satisfaction around procedural comfort increased by $5 \%$ \& annual mean score improvement correlated with the intervention with a centerline shift, with 8 consecutive points above baseline.

Improved $\mathrm{K} \& \mathrm{~A}$ between pretest \& post-test score

$(15.69 \pm 2.94$ vs. $17.51 \pm 3.47, p<.05)$ as well as the

$(15.69 \pm 2.94$ vs. $17.51 \pm 3.47, p<.05)$ as well as the
pretest \& retention score $(15.69+2.94$ vs. $19.40 \pm 4.6$ $p<.05$ ).
Low; 2

Moderate; $2-3$

Moderate; 2

Moderate; 2

Moderate; 3
Moderate; 2

Low: 2

Low; 2

\section{Moderate; 3}

$\mathrm{P}=$ participants at a data collection point; $\mathrm{P} 1$ = participants at first point of data collection; $\mathrm{P} 2=$ participants at second point of data collection; P3 = participants at third point of data collection; I = intervention group;

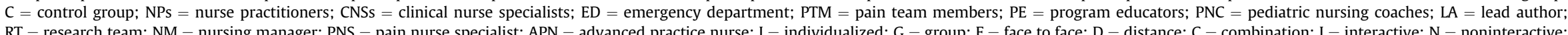
$\mathrm{BP}=$ bac princi $\mathrm{PA}=\mathrm{pan}$ a $\mathrm{BP}=$ basic electrical nervous stimulation; $N=$ number of participants: $M D=$ mean difference. 
stay (1 of 37 ), and adverse outcomes of pain management interventions ( 1 of 37 ).

Our analysis revealed that study outcomes were mainly assessed at two time points (22 of 37) followed by three time points ( 8 of 37). The frequency of outcome assessment was unreported in one study (Bildner \& Krechel, 1996).

\section{Which Aspects of the Education Contributes to Its Effectiveness?}

Participants' knowledge improved in 18 out of the 19 studies that reported on this outcome, whereas no knowledge difference was reported in 1 study (Habich et al., 2012). However, the magnitude of knowledge improvement could not be determined because of the heterogenous nature of the study reports. Participants' attitude improved in $75 \%$ of the studies that reported on this outcome (15 of 20) and declined in one study (He et al., 2010). No difference in attitude was reported in the remaining four studies. The practice of pain assessment, management, and/or documentation improved in 28 out of the 30 studies and worsened in 1 study (Knoblauch \& Wilson, 1999). While some aspects of practice (usage of non-pharmacological interventions) improved in the remaining study (He et al., 2011), no difference in other practice areas (nurses' provision of preparatory information to parents) was reported.

Participants evaluated the educational program as well organized, engaging, easy to understand and use, and meeting their expectations to a moderate-high extent in three studies. Patient/ family satisfaction improved in two studies (by $\leq 5 \%$ ), and no difference was reported in one study. Although patients' pain report at discharge improved in the only study that reported on this outcome, no difference was reported in the duration of mechanical ventilation, length of hospitalization, and adverse outcomes of pain management interventions for children in pain.

Content analysis of successful interventions revealed six themes: multidisciplinary collaboration, responsive program development, well-designed educational intervention, inclusiveness, system integration, and measures of securing sustainability.

Multidisciplinary teams were formed and involved in activities that contributed to the success of the educational interventions. For instance, it was reported in the 2012 study by Corwin et al. that:

After the initial data collection, a multidisciplinary committee was formed, composed of faculty and senior house staff from the departments of pediatrics, emergency medicine, and anesthesiology, as well as nursing leadership from the child life service. The committee reviewed preintervention data and developed a pain policy, structured around areas of poor performance, changes we thought were feasible to make, and existing guidelines for care standards that were not being met.

As part of the processes involved in developing the educational programs, several activities were undertaken to ensure that the program responds to the needs of stakeholders. These activities, which justified the need for the desired change, included the establishment of a pain educational needs assessment and reflection on current practices, among others. Excerpts of these have been outlined as follows:

Inclusion of the preliminary chart audit results were also used to justify the need for practice change ... nurses to reflect on their current practice; to help to foster the need for a change in attitudes and beliefs surrounding pain assessment and management; and to change practice for assessing pain in children with disabilities
The well-designed program constituted the intervention deliverer, frequency, duration, delivery mode, and content, all of which have been presented in Table 1 . Other inherent features that contributed to the program's effectiveness included clearly defined goals, teaching and learning resources, and sequencing of the educational program, among others. One study reported the following:

[The program was] implemented in 3 stages: development of an education booklet, booklet distribution, and lecture sessions.

-He, Vehvilainen-Julkunen, Pietila \& Polkki (2008).

The success of the educational interventions can also be attributed to inclusiveness measures that ensured that as many participants as possible were captured. This was illustrated in the following quote:

The researcher employed several alternative strategies to reach more staff nurses, including posting inservice content and case study material in PEDI and PICU nurse stations, charting rooms, and staff lounges; placing a copy of the inservice hand-out and case study materials in every staff nurse's mail box/folder; and requesting their written response regarding whether or not they read the content.

-Hong, Murphy, \& Connolly (2008).

One of the critical measures for effectiveness can be attributed to the incorporation of pain assessment and management into existing structures and systems. For instance:

...The following children's pain-related instruments were approved by the institution as permanent medical records.

—Howell, Foster, Hester, Vojir, \& Miller (1996).

Key among the contributing factors for the educational success was the sustainability measures that were instituted to support the desired change. They mainly centered on continual engagement measures, as found in the following quote:

Unit-based champions ... served as coaches and mentors during the implementation phase ... an advocate was designated on each shift to answer questions, solve problems, and generally instill positive attitudes among staff ... and the need for best practice pain management... feedback to and from nursing staff through members of the PRN group and the Nursing Pain Management Committee... Other transfer strategies to bring the CPMP to the bedside included presentations at nursing rounds, promotion via e-mail and hospital newsletters, unit-based pain information pegboards.

—Ellis et al. (2007b).

\section{Discussion}

This integrative review is the first to examine the effect of educational interventions targeted for nurses on pediatric pain assessment and management. Drake and de C. William's review described the effects of nursing educational interventions on clinical outcomes of acute pain management in hospital settings using 12 studies (Drake \& de C. Williams, 2017). None of the studies used in their review were included in our study because they were not focused on children's pain assessment and management. 
Our review results indicate that studies conducted in this field are predominantly quasi-experimental designs, with few scientifically robust designs such as RCTs. Although quasi-experimental designs are often used when researchers encounter difficulties in randomly allocating participants or working with small sample sizes, they pose some threats to establishing causality (Thyer, 2012). They are unable to sufficiently control for important confounding variables because of the lack of randomization. RCTs offer the best ways of establishing an intervention's effectiveness because of the robust nature of selecting and allocating participants to groups and assessing outcomes (Wludyka, 2012). Hence, there is the need for more methodologically sound RCTs to be conducted in this area.

Studies included in this review were mainly of moderate methodologic quality based on their total critical appraisal scores. Although this approach is essential in estimating the confidence level of research findings (Harrison, Reid, Quinn, \& Shenkin, 2017), it can be misleading because studies can be rated highly even when they contain potentially serious flaws (O'Connor et al., 2015). The adequacy of sample sizes in most studies were small, unjustified, and unreported in some instances. All these create difficulties in making conclusions that can be applied in other contexts (Suresh \& Chandrashekara, 2012).

Few primary studies were conducted in developing countries and none in Africa. The management of pediatric pain as a global health issue may require greater efforts in developing countries relative to developed countries because of limited resources and training deficits (Clancy, 2014). This therefore indicates a need for extension of the research evidence in low-resourced settings to determine which educational interventions will be effective in making an impact.

It is also worth mentioning that the majority of educational interventions were group based, organized via face-to-face and involved interactional teaching and learning approaches. Although these methods are recommended as effective (Curran, 2014), innovative pedagogic approaches such as problem-based learning, flipped classroom, and simulation, among others, were sparingly used in the included studies. As pedagogic approaches expand, it is important to evaluate how these emerging nursing educational methods affect research outcomes.

A good number of the studies did not give a comprehensive report on the educational interventions. Although journal article requirements remain strict on word counts for various reasons such as preventing boredom and presenting concise information (Davis, 2014), authors should not use this as an excuse for not reporting on important elements of an intervention. It is therefore recommended for authors to consult recognized guidelines (Hoffmann et al., 2014) when reporting on interventions.

With majority of studies evaluating knowledge, attitudes, and practice of pain assessment and or management, incoming studies should concentrate on the other outcomes such as program evaluation and patient and family satisfaction because of their limited evidence. Almost all of the studies included a baseline assessment indicator; however, it was unclear whether those results were used for planning interventions. Most follow-up assessments occurred immediately after the education, with few longitudinal evaluations. It thus remains inconclusive on the basis of this review and other literature (Beck et al., 2010; Gitlin \& Czaja, 2016) to determine the best time to measure the outcome and sustenance of an educational intervention because varied time intervals yielded positive results.

The success of the education can be attributed to multidisciplinary collaboration because this approach enables practitioners to better understand their roles and how different professions complement each other (Bedwell et al., 2012). With a growing emphasis on cocreation of interventions (Leask, Sandlund, Skelton,
\& Chastin, 2017), conducting an educational needs assessment in some studies served as the basis for addressing identified gaps and resulted in success, as has been reported in other studies (EkirapaKiracho et al., 2016; Tetui et al., 2017).

The educational inclusiveness measures facilitated the program's appeal to learners and encapsulated many participants, all of which propelled the desired changes. In addition, the integration of children's pain assessment and management into existing structures and sustainability measures contributed immensely to the success of the educational interventions, as reported in previous studies (Hanson, Salmoni, \& Volpe, 2009; Tricco et al., 2016).

\section{Strengths and Limitations}

Some of the strengths of this review lie in the inclusion of all study designs that were published up to 2017. Moreover, conclusions can be regarded as sound because they were based on studies with mainly moderate risk of bias.

Like many other studies, our review was not without some limitations, which should be considered when analyzing the findings. We did not review the gray literature, potentially predisposing our findings to a publication bias. Our review focused on three languages, excluding many others that possibly could have enhanced the evidence generated.

\section{Implications for Nursing Practice}

Various types of educational strategies improve nurses' knowledge, attitudes, and practice of pain assessment and management. Developing a responsive program that includes expectations of beneficiaries, integrating it into existing facility training systems, and delivering it through multidisciplinary collaboration offers the benefit of securing sustainability of educational gains. The search for which aspects of education contribute to its effectiveness should continue because this remains elusive.

This review recommends the following:

- True experimental designs with high methodological quality in this area

- Primary studies to be carried out in low-resource settings

- Examination of innovative teaching and learning approaches in nursing research

- Reporting on relevant outcomes for stakeholders in children's pain assessment and management

\section{Acknowledgments}

The authors are grateful to the following persons for their contributions: Leeni Lehtiö for helping us with the literature searching, Philemon Amooba for assisting us in getting the full-text articles of some studies, Luis Eduardo Juarez Orozco for providing us with insights on how to analyze the review results, and our colleagues at the Department of Nursing Sciences, University of Turku for their constructive criticisms and feedback.

\section{Supplementary Data}

Supplementary data related to this article can be found online at https://doi.org/10.1016/j.pmn.2019.03.005.

\section{References}

Abed El-Rahman, M., Al Kalaldeh, M. T., \& Muhbes, F. (2013). Knowledge and attitude towards pain management. A comparison between oncology and non- 
oncology nurses in Jordan. International Journal of Advanced Nursing Studies, 2(2), 95-100.

Argoff, C. E. (2014). Recent management advances in acute postoperative pain. Pain Practice, 14(5), 477-487.

Aziato, L., \& Adejumo, O. (2014). Determinants of nurses' knowledge gap on pain management in Ghana. Nurse Education in Practice, 14(2), 195-199.

Bachiocco, V., Gentili, A., Mastrolia, A., Lima, M., \& Baroncini, S. (2005). A pain educational program for pediatric nurses: Topics and key points. Medical and Surgical Pediatrics, 27(6), 34-37.

Beck, C., McSweeney, J. C., Richards, K. C., Roberson, P. K., Tsai, P. F., \& Souder, E. (2010). Challenges in tailored intervention research. Nursing Outlook, 58(2), 104-110.

Bedwell, W. L., Wildman, J. L., DiazGranados, D., Salazar, M., Kramer, W. S., \& Salas, E. (2012). Collaboration at work: An integrative multilevel conceptualization. Human Resource Management Review, 22(2), 128-145.

Bildner, J., \& Krechel, S. W. (1996). Increasing staff nurse awareness of postoperative pain management in the NICU. Neonatal Network, 15(1), 11-16.

Birnie, K. A., Chambers, C. T., Fernandez, C. V., Forgeron, P. A., Latimer, M. A., McGrath, P. J., Cummings, E. A., \& Finley, G. A. (2014). Hospitalized children continue to report undertreated and preventable pain. Pain Research and Management, 19(4), 198-204.

Bushnell, M. C., Čeko, M., \& Low, L. A. (2013). Cognitive and emotional control of pain and its disruption in chronic pain. Nature Reviews Neuroscience, 14(7), 502-511.

Chan, S., Pielak, K., McIntyre, C., Deeter, B., \& Taddio, A. (2013). Implementation of a new clinical practice guideline regarding pain management during childhood vaccine injections. Paediatrics and Child Health, 18(7), 367-372.

Chiang, L.-C., Chen, H.-J., \& Huang, L. (2006). Student nurses' knowledge, attitudes, and self-efficacy of children's pain management: Evaluation of an education program in Taiwan. Journal of Pain and Symptom Management, 32(1), 82-89.

Chiaretti, A., Pierri, F., Valentini, P., Russo, I., Gargiullo, L., \& Riccardi, R. (2013). Current practice and recent advances in pediatric pain management. European Review for Medical and Pharmacological Sciences, 17(Suppl 1), 112-126.

Cilliers, F. J., \& Herman, N. (2010). Impact of an educational development programme on teaching practice of academics at a research-intensive university. International Journal for Academic Development, 15(3), 253-267.

Clancy, M. A. (2014). Difficulty, despair and hope - an insight into the world of the health professionals treating paediatric pain in sub-saharan Africa. Journal of Research in Nursing, 19(3), 191-210.

Corwin, D. J., Kessler, D. O., Auerbach, M., Liang, A., \& Kristinsson, G. (2012). An intervention to improve pain management in the pediatric emergency department. Pediatric Emergency Care, 28(6), 524-528.

Cousins, M. J. (2012). Unrelieved pain: A major health care priority. Medical Journal of Australia, 196(6), 373-374.

Curran, M. K. (2014). Examination of the teaching styles of nursing professional development specialists, part I: Best practices in adult learning theory, curriculum development, and knowledge transfer. The Journal of Continuing Education in Nursing, 45(5), 233-240.

Davis, G. F. (2014). Editorial essay: Why do we still have journals? Administrative Science Quarterly, 59(2), 193-201.

Deindl, P., Unterasinger, L., Kappler, G., Werther, T., Czaba, C., Giordano, V., Frantal, S., Berger, A., Pollak, A., \& Olischar, M. (2013). Successful implementation of a neonatal pain and sedation protocol at 2 NICUs. Pediatrics, 132(1), e211-e218.

Dongara, A. R., Nimbalkar, S. M., Phatak, A. G., Patel, D. V., \& Nimbalkar, A. S. (2017). An educational intervention to improve nurses' understanding of pain in children in western India. Pain Management Nursing, 18(1), 24-32.

Drake, G., \& de C. Williams, A. C. (2017). Nursing education interventions for managing acute pain in hospital settings: A systematic review of clinical outcomes and teaching methods. Pain Management Nursing, 18(1), 3-15.

Ekim, A., \& Ocakci, A. F. (2013). Knowledge and attitudes regarding pain management of pediatric nurses in Turkey. Pain Management Nursing, 14(4), e262-e267.

Ekirapa-Kiracho, E., Namazzi, G., Tetui, M., Mutebi, A., Waiswa, P., Oo, H., Peters, D. H., \& George, A. S. (2016). Unlocking community capabilities for improving maternal and newborn health: Participatory action research to improve birth preparedness, health facility access, and newborn care in rural Uganda. BMC Health Services Research, 16, 93-104.

Ellis, J. A., Martelli, B., LaMontagne, C., \& Splinter, W. (2007a). Evaluation of a continuous epidural analgesia program for postoperative pain in children. Pain Management Nursing, 8(4), 146-155.

Ellis, J. A., McCleary, L., Blounin, R., Dube, K., Rowley, B., MacNeil, M., \& Cooke, C. (2007b). Implementing best practice pain management in a pediatric hospital. Journal for Specialists in Pediatric Nursing, 12(4), 264-277.

Francis, L., \& Fitzpatrick, J. J. (2013). Postoperative pain: Nurses' knowledge and patients' experiences. Pain Management Nursing, 14(4), 351-357.

Gallo, A. (2003). The fifth vital sign: Implementation of the neonatal infant pain scale. Journal of Obstetric, Gynecologic \& Neonatal Nursing, 32(2), 199-206.

Gitlin, L. N., \& Czaja, S. J. (2016). Behavioral intervention research: Designing, evaluating, and implementing. New York: Springer.

Greenhalgh, T., Robert, G., Macfarlane, F., Bate, P., \& Kyriakidou, O. (2004). Diffusion of innovations in service organizations: Systematic review and recommendations. Milbank Quarterly, 82(4), 581-629.

Habich, M., \& Letizia, M. (2015). Pediatric pain assessment in the emergency department: A nursing evidence-based practice protocol. Pediatric Nursing, 41(4), 198-202.
Habich, M., Wilson, D., Thielk, D., Melles, G. L., Crumlett, H. S., Masterton, J., \& McGuire, J. (2012). Evaluating the effectiveness of pediatric pain management guidelines. Journal of Pediatric Nursing, 27(4), 336-345.

Hanson, H. M., Salmoni, A. W., \& Volpe, R. (2009). Defining program sustainability: Differing views of stakeholders. Canadian Journal of Public Health, 100(4), 304-309.

Harrison, J. K., Reid, J., Quinn, T. J., \& Shenkin, S. D. (2017). Using quality assessment tools to critically appraise ageing research: A guide for clinicians. Age and Ageing, 46(3), 359-365.

He, H. G., Jahja, R., Lee, T. L., Ang, E. N. K., Sinnappan, R., Vehviläinen-Julkunen, K., \& Chan, M. F. (2010). Nurses' use of non-pharmacological methods in children's postoperative pain management: Educational intervention study. Journal of Advanced Nursing, 66(11), 2398-2409.

He, H. G., Jahja, R., Sinnappan, R., Ang, E. N. K., Lee, T. L., Chan, M. F., \& VehviläinenJulkunen, K. (2011). Singaporean nurses' provision of guidance to parents on non-pharmacological postoperative pain-relief methods: An educational intervention study. Nursing and Health Sciences, 13(3), 344-351.

He, H., Vehvilainen-Julkunen, K., Pietila, A., \& Polkki, T. (2008). Increasing nurses knowledge and behavior changes in nonpharmacological pain management for children in China. Journal of Nursing Care Quality, 23(2), 170-176.

Heinrich, M., Mechea, A., \& Hoffmann, F. (2016). Improving postoperative pain management in children by providing regular training and an updated pain therapy concept. European Journal of Pain, 20(4), 586-593.

Higgins, J. P., \& Green, S. (2008). Cochrane handbook for systematic reviews of interventions: Cochrane book series. Chichester, England: Wiley.

Hightower, A. M., Lloyd, S. C., \& Swanson, C. B. (2011). Improving student learning by supporting quality teaching: Key issues, effective strategies. Bethesda, MD: Editorial Projects in Education, Inc.

Hoffmann, T. C., Glasziou, P. P., Boutron, I., Milne, R., Perera, R., Moher, D., Altman, D. G., Barbour, V., Macdonald, H., Johnston, M., Lamb, S. E., DixonWoods, M., McCulloch, P., Wyatt, J. C., Chan, A. W., \& Michie, S. (2014). Better reporting of interventions: Template for intervention description and replication (TIDieR) checklist and guide. British Medical Journal, 348, g1687.

Hong, S. S., Murphy, S. O., \& Connolly, P. M. (2008). Parental satisfaction with nurses communication and pain management in a pediatric unit. Pediartric Nursing, 34(4), 306-307.

Howell, S. L., Foster, R. L., Hester, N. O., Vojir, C. P., \& Miller, K. L. (1996). Evaluating a pediatric pain management research utilization program. Canadian Journal of Nursing Research, 28(2), 37-57.

Huth, M. M., Gregg, T. L., \& Lin, L. (2010). Education changes Mexican nurses' knowledge and attitudes regarding pediatric pain. Pain Management Nursing 11(4), 201-208.

Jain, A. a, Yeluri, R., \& Munshi, A. K. (2012). Measurement and assessment of pain in children: A review. The Journal of Clinical Pediatric Dentistry, 37(2), 125-136.

Johnston, C. C., Gagnon, A., Rennick, J., Rosmus, C., Patenaude, H., Ellis, J., Shapiro, C. Filion, F., Ritchie, J., \& Byron, J. (2007). One-on-one coaching to improve pain assessment and management practices of pediatric nurses. Journal of Pediatric Nursing, 22(6), 467-478.

Kingsnorth, S., Joachimides, N., Krog, K., Davies, B., \& Higuchi, K. S. (2015). Optimal pain assessment in pediatric rehabilitation: Implementation of a nursing guideline. Pain Management Nursing, 16(6), 871-880.

Knoblauch, S. C., \& Wilson, C. J. (1999). Clinical outcomes of educating nurses about pediatric pain management. Outcomes Management for Nursing Practice, 3(2), 87-89.

Le May, S., Johnston, C. C., Choinière, M., Fortin, C., Kudirka, D., Murray, L., \& Chalut, D. (2009). Pain management practices in a pediatric emergency room (PAMPER) study: Interventions with nurses. Pediatric Emergency Care, 25(8), 498-503.

Leask, C. F., Sandlund, M., Skelton, D. A., \& Chastin, S. F. M. (2017). Co-creating a tailored public health intervention to reduce older adults' sedentary behaviour Health Education Journal, 76(5), 595-608.

Lunsford, L. (2015). Knowledge and attitudes regarding pediatric pain in Mongolian nurses. Pain Management Nursing, 16(3), 346-353.

Mazur, A., Radziewicz Winnicki, I., \& Szczepański, T. (2013). Pain management in children. Annals of Agricultural and Environmental Medicine, 1, 28-34.

Maclaren, J. E., Cohen, L. L., Larkin, K. T., \& Shelton, E. N. (2008). Training nursing students in evidence-based techniques for cognitive-behavioral pediatric pain management. Journal of Nursing Education, 47(8), 351-358.

National Heart, Lung and Blood Institute. (2019). Study quality assessment tools. Retrieved from https://www.nhlbi.nih.gov/health-topics/study-quality-assess ment-tools. (Accessed 8 March 2018).

Noel, M., Chambers, C. T., McGrath, P. J., Klein, R. M., \& Stewart, S. H. (2012). The influence of children's pain memories on subsequent pain experience. Pain, 153(8), 1563-1572.

Nissen, S., \& Dunford, C. (2014). Assessment of pain in children with brain injury: Moving to best practice. British Journal of Nursing, 23(17), 930-934.

O’Connor, S. R., Tully, M. A., Ryan, B., Bradley, J. M., Baxter, G. D., \& McDonough, S. M. (2015). Failure of a numerical quality assessment scale to identify potential risk of bias in a systematic review: A comparison study. BMC Research Notes, 8, 224.

Overmeer, T., Boersma, K., Denison, E., \& Linton, S. J. (2011). Does teaching physical therapists to deliver a biopsychosocial treatment program result in better patient outcomes? A randomized controlled trial. Physical Therapy, 91(5), 804-819.

Owens, D., Smith, J., \& Jonas, D. (2014). Evaluating students' knowledge of child pain and its management after attending a bespoke course. Nursing Children and Young People, 26(2), 34-40. 
Pederson, C. (1996). Nonpharmacologic interventions to manage children's pain: Immediate and short-term effects of a continuing education program. Journal of Continuing Education in Nursing, 27(3), 131-140.

Pluye, P., Robert, E., Cargo, M., \& Bartlett, G. (2011). Mixed method appraisal tool (MMAT) (Version 2011). Retrieved from http://mixedmethodsappraisaltool public.pbworks.com/w/file/fetch/84371689/MMAT\%202011\%20criteria\%20and\% 20tutorial\%202011-06-29updated2014.08.21.pdf. (Accessed 8 March 2018).

Predebon, C. M., de Almeida Lopes Monteiro da Cruz, D., de Oliveira Azevedo Matos, F. G., Ferreira, A. M., Pasin, S., \& Rabelo, E. R. (2015). Evaluation of pain and accuracy diagnostic in hospitalized children. International Journal of Nursing Knowledge, 23(2), 106-113.

Ramira, M. L., Instone, S., \& Clark, M. J. (2016). Pediatric pain management: An evidence-based approach. Pediatric Nursing, 42(1), 39-50.

Reavey, D. A., Haney, B. M., Atchison, L., Anderson, B., Sandritter, T., \& Pallotto, E. K. (2014). Improving pain assessment in the NICU: A quality improvement project. Advances in Neonatal Care, 14(3), 144-153.

Rosenberg, R. E., Klejmont, L., Gallen, M., Fuller, J., Dugan, C., Budin, W., \& OlsenGallagher, I. (2016). Making comfort count: Using quality improvement to promote pediatric procedural pain management. Hospital Pediatrics, 6(6), $359-368$.

Scott, L. E., Crilly, J., Chaboyer, W., \& Jessup, M. (2013). Paediatric pain assessment and management in the emergency setting: The impact of a paediatric pain bundle. International Emergency Nursing, 21(3), 173-179.

Simons, J. M., \& MacDonald, L. M. (2006). Changing practice: Implementing validated paediatric pain assessment tools. Journal of Child Health Care, 10(2), 160-176.

Simons, J. M. (2002). An action research study exploring how education may enhance pain management in children. Nurse Education Today, 22(2), 108-117.

Srouji, R., Ratnapalan, S., \& Schneeweiss, S. (2010). Pain in children: Assessment and nonpharmacological management. International Journal of Pediatrics, 2010, 474838.
Suresh, K., \& Chandrashekara, S. (2012). Sample size estimation and power analysis for clinical research studies. Journal of Human Reproductive Sciences, 5(1), 7.

Tacconelli, E. (2010). Systematic reviews: CRD's guidance for undertaking reviews in health care. The Lancet Infectious Diseases, 10(4), 226.

Taddio, A., Shah, V., Wang, J., Parikh, C., Smart, S., Ipp, M., Riddell, R. P., \& Franck, L. S. (2015). Usability and knowledge testing of educational tools about infant vaccination pain management directed to postnatal nurses. BMC Medical Education, 15(1), 45.

Tetui, M., Coe, A.-B., Hurtig, A.-K., Bennett, S., Kiwanuka, S. N., George, A., \& Kiracho, E. E. (2017). A participatory action research approach to strengthening health managers' capacity at district level in Eastern Uganda. Health Research Policy and Systems, 15(Suppl. 2), 110.

Thyer, B. A. (2012). Quasi-experimental research designs. Oxford Scholarship Online. Retrieved from https://doi.org/10.1093/acprof:0so/9780195387384.001.0001. (Accessed 8 March 2018).

Tricco, A. C. Ashoor, H. M., Cardoso, R., MacDonald, H., Cogo, E., Kastner, M. Perrier, L., McKibbon, A., Grimshaw, J. M., \& Straus, S. E. (2016). Sustainability of knowledge translation interventions in healthcare decision-making: A scoping review. Implementation Science, 11, 55.

Twycross, A. (2013). Nurses' views about the barriers and facilitators to effective management of pediatric pain. Pain Management Nursing, 14(4), e164-e172.

Twycross, A. (2010). Managing pain in children: Where to from here? Journal of Clinical Nursing, 19(15-16), 2090-2099.

Vael, A., \& Whitted, K. (2014). An educational intervention to improve pain assessment in preverbal children. Pediatric Nursing, 40(6), 301-302.

Van Hulle, V. C., Wilkie, D. J., \& Wang, E. (2011). Pediatric nurses' beliefs and pain management practices. Western Journal of Nursing Research, 33(6), 825-845.

Wludyka, P. (2012). Study designs and their outcomes. In K. Macha, \& J. P. McDonough (Eds.), Epidemiology for advanced nursing practice (pp. 81-114). Burlington, MA: Jones \& Barlett Learning. 